\title{
KOMUNIKASI VISUAL KARTUN SOMPRET KARYA I WAYAN SADHA
}

\author{
I Wayan Nuriarta ${ }^{1}$, I Gede Agus Indram Bayu Artha², Ni Putu Dhea Pramesti ${ }^{3}$, Pande \\ Putu Sastra Wibawa ${ }^{4}$ \\ Jurusan Desain Komunikasi Visual, Fakutas Seni Rupa dan Desain, \\ Institut Seni Indonesia Denpasar
}

\begin{abstract}
This paper was written to read visual signs and verbal marks contained in the cartoon Sompret by I Wayan Sadha. I Wayan Sadha's Sompret cartoon has its uniqueness as a work of visual communication. The uniqueness is that the visual communication of this cartoon presents illustrations, typography, and layouts with a deep appreciation of Balinese culture. The illustration presents a Balinese wearing a headdress is a representation of a Balinese in traditional culture. The illustration of a Balinese without a headdress is a representation of a Balinese who is in the modern culture. The typography used utilizes the display font to present the conversation and clarify the description of the image. The letters are used to explain the issue raised as Sadha's opinion and point of view on the Bali issues. Sadha's Sompret Cartoons only use lines, no color, so his works appeared as black and white cartoons. Sompret cartoons used the symmetrical balance composition and hidden balance layout, the perspective of human eye level, and the perspective of a bird's eye. This research uses descriptive qualitative research method. Semiotic theory is used in this research and focus on denotation and connotation meaning. Denotationally, the Sompret cartoon of Sadha presents a narrative of events based on the issue raised related to Balinese traditional culture and the flow of globalization. The work is created in a one-panel cartoon. The story of this cartoon sometimes with conversations of several characters or only illustrations of the characters without any conversation. With the narrative being built, the meaning of the connotation can be read. The connotations meaning of Sompret cartoons as opinion cartoons is showing the flow of globalization or modern culture in the middle of the strength of the Balinese traditional culture. Connotatively this cartoon can be read as a development of globalization in Bali.
\end{abstract}

\footnotetext{
1 iwayannuriarta@gmail.com

2 goesindram@gmail.com

3 dheapramesti3@gmail.com

${ }^{4}$ sastraw22@gmail.com
} 


\section{PENDAHULUAN}

Kartun merupakan karya komunikasi visual yang representasi atau simbolik untuk menghadirkan tawa dan atau kritik. Secara umum, kartun dapat dibagi menjadi dua jenis yaitu; (1) Kartun murni (gag cartoon) yaitu sebuah kartun humor yang biasanya menghadirkan lelucon ataupun humor yang bisa membuat pembacanya tertawa saat melihat gambar tersebut, dan (2) Kartun editorial (editorial cartoon) yang digunakan sebagai visualisasi tajuk rencana sebuah media. Kartun ini biasanya membicarakan masalah politik ataupun masalah-masalah aktual yang menjadi berita utama dari redaksi, sehingga bisa juga disebut sebagai kartun politik atau kartun kritik. Kekuatan utama dari sebuah kartun terletak pada ide. Kartun Sompret karya I Wayan Sadha adalah kartun kritik.

Kartun-kartunnya menghadirkan opini yang berupa kritik terhadap masuknya arus globalisasi atas terbukanya Bali sebagai daerah pariwisata. Pada masa sekarang ini, tak satupun masyarakat kemudian dapat melepaskan diri dari pengaruh budaya luar karena terbukanya arus pariwisata. Kritik terhadap perubahan budaya pada masyarakat Bali menjadi isu yang diangkat Kartun Sompret. I Wayan Sadha sebagai seorang kartunis Bali, mengingatkan pembacanya/ masyarakat terkait dengan pengaruh arus globalisasi. Lebih-lebih masyarakat Bali yang sudah sejak awal memposisikan wilayahnya sebagai wilayah tujuan pariwisata seiring dengan kebijakan kolonial dalam Baliseering atau Balinisasi Bali.
Perkembangan pariwisata sangat memberikan keuntungan secara material bagi kebanyakan masyarakat Bali. Hanya saja dampak negatif juga menjadi konsekuensi dari pergaulannya dengan masyarakat luar dan masyarakat asing yang sering kali tidak disadari oleh banyak pihak. Perubahanperubahan tersebut akan membawa dampak pula pada tradisi budaya Bali yang sudah mapan. Akhirnya meruntuhkan keberadaan budaya, lalu digantikan oleh budaya dan nilai-nilai luar yang dalam hal ini tidak sesuai dengan masyarakat Bali tradisional. I Wayan Sadha memang tidak memusuhi budaya luar yang masuk ke tengah-tengah masyarakat. Hanya saja dengan pengamatan yang dilakukannya sebagai salah satu orang Bali, ia mengingatkan untuk pandai-pandai memilah dan memilih nilai-nilai yang tepat untuk budaya (tradisional) Bali. Ada kekhasan tersendiri yang dimiliki Kartun Sompret karya I Wayan Sadha jika dibandingkan dengan karya kartunis Indonesia maupun Bali pada khususnya. Pertama, kekhasan itu adalah keterikatannya dengan budaya Bali. Penghayatannya yang mendalam pada budaya Bali menghadirkan kartun Sompret sebagai representasi opininya terhadap berbagai persoalan yang melanda budaya Bali.

Kartun Sompret memberikan kritik dalam berbagai aspek kehidupan. Kedua, dari segi penggunaan bahasa, Kartun Sompret karya I Wayan Sadha juga menunjukan keunggulannya. Dialogdialog bahasa Indonesia yang ditampilkan dengan campuran ungkapan-ungkapan dan 
ekspresi-ekspresi yang khas milik orang Bali, bukan milik budaya-budaya lain. Ketiga, tokohtokoh kartunnya benar-benar merepresentasikan masyarakat Bali dengan berbagai persoalan kehidupan keseharian. Keempat, Kartun-kartun yang dihadirkan merupakan potret kehidupan masyarakat Bali yang paradoks tentang budaya Bali dan masuknya arus globalisasi. Bali yang harusnya tetap sebagai museum hidup atas kebijakan Baliseering, malah tumbuh sebagai Bali yang modern karena pariwisata. Dengan catatan diatas, dapat dikatakan bahwa sebagai produk budaya popular, Kartun Sompret menjadi menarik untuk diperiksa bagaimana harapan dan penerimaan masyarakat terhadap berbagai perubahan kebudayaan yang berlangsung. Kartun ini semakin penting untuk dikaji karena wacana yang dihadirkan menjadi situs perjuangan ideologi. Pada penelitian ini akan membahas kombinasi elemen grafis yang berkaitan dengan visualisasi kartun yaitu; ilustrasi, tipografi, warna dan layout untuk mendeskripsikan bentuk Kartun Sompret. Sedangkan makna denotasi dan makna konotasi dibahas untuk mendapatkan kedalaman makna yang disampaikan dalam narasi Kartun Sompret karya I Wayan Sadha.

Kajian ini sangat tepat dikaji menggunakan teori semiotika. Penelitian ini menggunakan rancangan kualitatif. Segala hal yang berhubungan dengan Kartun Sompret karya I Wayan Sadha akan dideskripsikan secara kualitatif. Langkah kualitatif yang dilakukan adalah mengumpulkan, menyaring dan menganalisis data untuk menghasilkan data deskriptif berupa kata-kata, catatan-catatan yang berhubungan dengan makna. Data tentang Kartun Sompret karya I Wayan Sadha dikumpulkan dengan metode observasi dan dokumentasi. Metode
Observasi dilakukan pada sejumlah Kartun Sompret tahun 1994 sampai dengan tahun 2008. Metode dokumentasi dilakukan dengan membaca sejumlah tulisan yang berkaitan dengan kartun, baik yang berada pada buku teks, jurnal maupun di media massa. Data yang telah terkumpul dianalisis dalam beberapa tahap. Analisis data menurut Moleong (2001: 103) adalah proses mengorganisasikan dan mengurutkan data ke dalam pola, kategori dan satuan uraian dasar sehingga dapat ditemukan tema dan hipotesis seperti yang disarankan data. Pengorganisasian dan pengurutan data itu disesuaikan dengan elemen grafis dan tahapan-tahapan analisis semiotika Roland Barthes.

\section{PEMBAHASAN}

\section{Kartun 1}

Kartun 1 ini dibuat pada tahun 1994 oleh I Wayan Sadha. Kartun satu panel ini menghadirkan ilustrasi dua orang manusia dan seekor ajing Bali. Perbincangan dua manusia laki-laki ini dibuat dalam setting ruangan galeri. Ilustrasi laki-laki paling kiri digambarkan dengan kostum masyarakat Bali dengan menggunakan destar dan kamen (kain). Wajahnya menghadap ke kanan, melihat ilustrasi manusia laki-laki yang ada di depannya. Ilustrasi manusia laki-laki yang digambarkan di sebelah kanan adalah ilustrasi dengan berpakaian seperti masyarakat Bali modern, memakai baju dan celana panjang. Ilustrasi paling kanan menggambarkan seekor anjing Bali dalam posisi duduk. Percakapanpun berlangusng dalam ruang Galeri.

Ruang Galeri sebagai setting percakapan diketahui dari adanya pajangan berbagai lukisan pada latar belakang gambar. Ruang inilah sebagai tempat percakapan berlangsung. Percakapan bisa 
kita baca pada balon kata dengan urutan baca dari kiri ke kanan, dari atas ke bawah. Maka kita akan dapat membaca percakapan tersebut dengan memulai percakapan dari ilustrasi manusia paling kanan, karena balon katanya terdapat pada posisi paling kiri atas. la berkata; Kenken kabare jani dini di Ubud, Nyak rame torise mabelanja? ( Bagaimana kabarnya di Ubud, apakah ramai tuisnya berbelanja?).

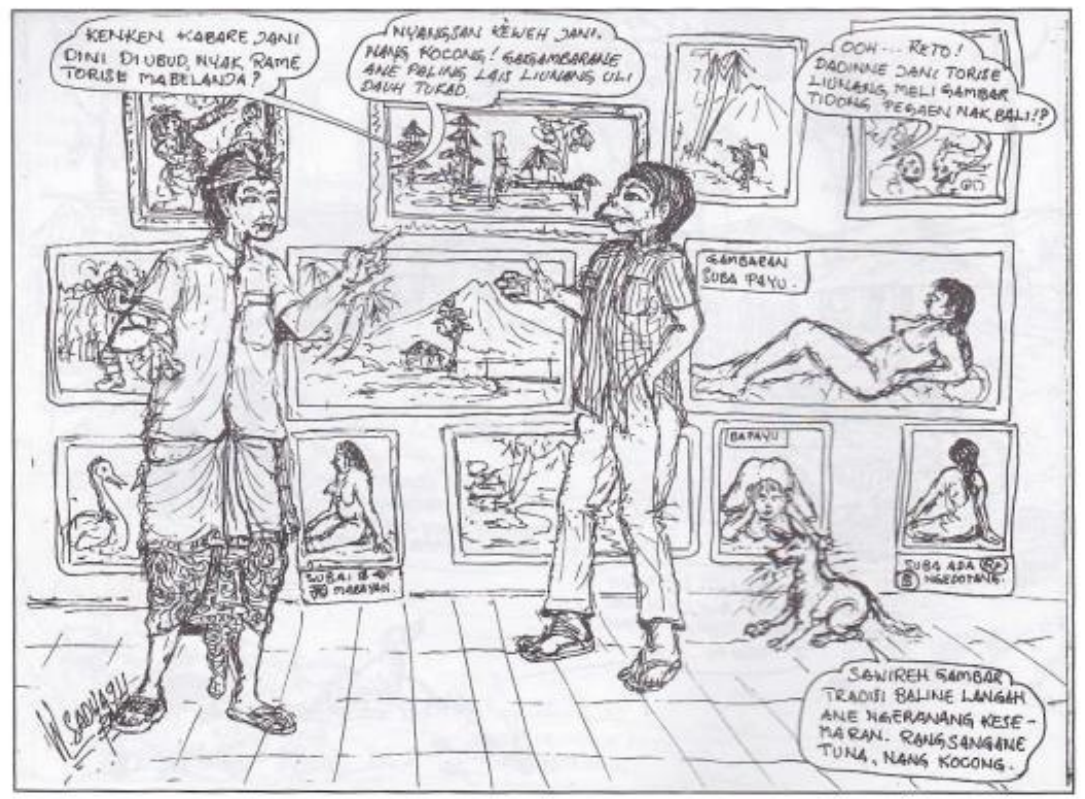

Gambar 1. Kartun Sompret Karya I Wayan Sadha tahun 1994

Pertanyaan tersebut kemudian dijawab oleh laki-laki yang memakai destar dengan berkata: Nyangsan keweh jani, Nang Kocong!Gagambarane Ane paling lais liunang uli dauh tukad ( Tambah susah sekarang Nang Kocong, gambar yang laku terjual kebanyakan karya pelukis Kartun 1. Kartun Sompret Karya I Wayan Sadha tahun 1994 dari luar). Selanjutnya ditanggapi kembali oleh laki-laki yang memakai celana panjang dengan berkata: ooh...keto! Dadinne jani torise liunang meli gambar tidong pegaen nak Bali!? (oh...begitu, jadi kebanyakan turis yang membeli lukisan hasil karya bukan orang Bali). Percakapan dua laki-laki tersebut ditanggapi oleh anjing Bali yang bernama Sompret dengan kata-kata pada balon kata paling kanan bawah, tulisannya: Sawireh gambar tradisi Baline langah ane ngeranang kesemaran. Rangsangane tuna Nang Kocong ( Karena lukisan tradisi Bali jarang yang merangsang birahi Nang Kocong).

Semua tulisan dalam percakapan ini menggunakan tipografi Scrip. Kartun Sompret karya I Wayan Sadha ini hanya memanfaatkan garis dalam menyampaikan komunikasinya secara visual, tanpa menggunakan warna. Dengan layout simetris pandangan sejajar mata manusia. Secara denotasi, kartun ini bercerita tentang situasi penjualan karya seni lukis di Ubud. Percakapan dua orang Bali dengan cara berpakaian khas Bali tradisional dengan menggunakan destar dan orang Bali modern dengan cara berpakaian menggunakan celana panjang. Percakapan berlangsung tepat di dalam galeri lukisan. Diantara lukisan-lukisan yang memiliki nuansa erotis, seksi dan sangat dekat dengan persoalan ketelanjangan tubuh perempuan. Percakapan dua laki-laki itu membahas 
tentang penjualan lukisan kini di Galeri. Perbincangan tersebut mengarah pada persoalan bahwa lukisan khas tradisional Bali yang biasanya berupa karya seni lukis tradisi Bali khas Ubud terdiri dari lukisan kisah pewayangan epos besar Ramayana dan Mahabharata. Lukisan yang biasanya bercerita tentang kepahlawanan Rama dalam perjalanan menyelamatkan istrinya Sita dari penculikan Raksasa Rahwana. Atau cerita tentang kebenaran ksatria Panca Pandawa yang terdiri dari Dharmawangsa, Bhima, Arjuna, Nakula dan Sahadewa ditemani oleh tokoh Khrisna yang mengalahkan kejahatan para Korawa yang dipimpin oleh tokoh Duryadana. Emos Ramayana dan Mahabharata selalu menjadi tema seni lukis tradisonal Bali termasuk di daerah Ubud. Pada Karya kartun ini justru yang dihadirkan pada galeri adalah lukisan perempuan yang telanjang. Nilai-nilai cerita kepahlawanan sontak tergantikan oleh karya seni lukis perempuan telanjang. Pergantian tema lukisan ini menjadi pernincangan khusus kedua lakilaki dalam kartun. Kartun anjing Bali yang bernama Sompret kemudian menegaskan kehadirannya lukisan perempuan telanjang di galeri karena persoalan penjualan lukisan yang laku. Hanya seni lukis perempuan telanjang yang banyak di Beli oleh para wisatawan, sehingga karya lukis perempuan telanjanglah yang banyak terpasang pada dinding galeri menggeser seni lukis tradisional wayang Bali.

Makna konotasi yang disampaikan dalam karya komunikasi visual kartun ini adalah terjadinya pergeseran objek karya seni yang diminati oleh pembeli. Pembeli lebih banyak membeli lukisan dengan model telanjang dengan melihat perempuan sebagai objek seninya. Dalam karya kartun ini, fokus utama pembahasan bukanlah ilustrasi dua laki-laki, namun kartun ini sedang memandang seni lukis perempuan telanjang sebagai persoalan yang dikemukakan. Lukisan-lukisan yang memperlihatkan perempuan model berada di ruang privat dan ruang tebuka. Ruang privat dicirikan dengan adanya penggambaran tempat tidur dan di ruang yang terbuka. Perempuan dalam lukisanluksan menjadi serupa tontonan yang diintip dalam ruang privat. Perempuan dalam lukisan dari perbincangan laki-laki ini jelas adalah objek. Pelukis adalah subjek yang mengatur dan memilih pose serta gesture perempuan yang dijadikan model lukisan.

Persoalan jual-beli lukisan yang mempengaruhi ekonomi masayarakat sangat kuat tersampaikan dalam karya kartun 1 ini. Penyebab terjadinya pergeseran jenis lukisan yang dijual di galeri di Ubud adalah persoalan jual-beli. Karya-karya yang diminati akan dibuat dan dipajang lebih banyak. Persoalan ekonomi menjadi persoalan utama. Persoalan ekonomi, jualbeli lukisan perempuan telanjang telah menggeser karya epos Ramayana dan Mahabharta. Seni lukis tradisional terseger oleh seni lukis modern. Artinya posisi tradisi dan budaya orang Bali mulai terjadi pergeseran karena adanya arus modernisasi. Perubahan atas modernitas ini mempengaruhi berbagai perkembangan masyarakat Bali.

Makna yang lainnya terhadap persoalan seni lukis perempuan telanjang yang terpajang di galeri tersebut juga memberikan makna tentang sensualitas dan kapitalisme. Dominasi pemanfaatan perempuan sesuai dengan pembahasan karya kartun diatas selanjutnya berdasarkan data yang ada secara empiris menunjukan makna dalam bentuk subordinatif dan eksploitatif. Perempuan yang terepresentasi dalam lukisan secara oprasional yang paling 
menyolok terutama yang berbasis pada akumulasi patologi ideologi gender dan system kapitalisme di masyarakat adalah berkaitan dengan tiga hal. Pertama, persoalan eksploitasi stereotip daya tarik seksualitas perempuan tersebut. Kedua, terkait dengan eksploitasi stereotip seksualitas perempuan tersebut, maka konsekuensinya adalah memunculkan adanya stereotip turunan yang terkait dengannya, yakni stereotip segenap bagian tubuh, serta ketiga yang tidak kalah dominannya adalah eksploitasi stereotip domestikisasi perempuan.

Persoalan eksploitasi stereotip daya tarik seksualitas serta organ tubuh perempuan yang mempunyai sex appeal yang tinggi, merupakan salah satu realitas yang amat ditunjukan pada perbincangan lukisan karya kartun 1. Tubuh perempuan menjadi daya tarik dalam berbagai proses sosial dan ekonomi guna memberikan daya tarik erotis pada seni lukis modern. Kekuatan daya tarik tersebut merupakan factor pendorong yang penting dan kuat untuk memverifikasi minat seseorang untuk membeli lukisan. Lukisan perempuan telanjang maknanya sama dengan sensualitas perempuan cantik, seksi dan muda yang semuanya itu menunjukan hasrat libido yang sangat menggoda, menyenangkan dan menggairahkan.

\section{Kartun 2}

Kartun 2 ini dibuat oleh Sadha pada tahun 2008. Dibuat dengan memanfaatkan satu panel atau satu frame dengan menghadirkan ilustrasi pada kiri panel tokoh laki-laki yang memegang teropong melihat kejauhan sambil menuliskan sesuatu dengan tangan kirinya pada buku tebal. Buku yang ditulis tersebut berada diatas meja yang dilengkapi oleh kain poleng. Ilustrasi laki-laki paling kiri ini dibuat dengan ciri-ciri rambut bagian atasnya rontok, sehingga yang tampak rambut pada kepala bagian belakang, telinganya besar, alis yang tebal. Tangannya menggunakan jam. Teropongnya yang panjang menunjukan Pulau Bali dengan tertancap bendera yang berisi tulisan Petani dan di tanah Bali bertuliskan Subur 1958. Pulau Bali pada lingkaran tropong sisi yang lainya menunjukan Bali berisi bendera yang bertuliskan GloBALIsasi-Politik-Investor dan tanah Bali bertuliskan Kerontang 2008. Ilustrasi manusia ini dibuat dengan ukuran yang sangat besar dengan tinggi hampir memenuhi tinggi panel.

Ilustrasi selanjutnya berada di bagian panel sebelah kanan dengan menghadirkan laki-laki memakai destar poleng duduk bersama seekor anjing Bali. Laki-laki berdestar dan anjing Bali Sompret tampat duduk bengong melihat tokoh yang ada di depannya. Laki-laki berdestar dan Sompret tidak mengeluarkan kata-kata apapun. Gambar ini tidak menghadirkan balon kata, yang artinya tidak ada percakapan. Tipografi hanya digunakan untuk keterangan gambar. Tipografi dengan memanfaatkan jenis huruf scrip. Tulisan tidak digunakan sebagai dialog antar tokoh. Tulisan hanya digunakan untuk keterangan peristiwa dan nama sesuatu untuk memudahkan membaca pesan secara visual. Kartun Sompret karya I Wayan Sadha ini hanya memanfaatkan garis dalam menyampaikan komunkasinya secara visual, tanpa menggunakan warna. Dengan layout memanfaatkan komposisi keseimbangan semu dan perspektif pandangan mata burung.

Secara denotasi, kartun 2 ini memiliki makna seorang yang memiliki tubuh besar dengan cara pandangnya menggunakan teropong melihat perubahan 
yang terjadi di Bali antara tahun 1958 dengan perubahan yang terjadi sampai pada tahun 2008. Perubahan yang digambarkan pada teropong menunjukan pulau Bali yang berbeda. Laki-laki besar ini memakai jam tangan dan mencatat berbagai perubahan yang terjadi. Sementara orang Bali yang ditemani anjingnya hanya duduk terdiam tanpa bisa berbuat apa-apa. Orang Bali hanya duduk diam melihat berbagai perubahan pulau Bali yang ditatapnya dalam ujung teropong. Anjing Bali dan orang Bali melihat pulau Bali tahun 1958, menatap pulau Bali yang subur, tanaman tumbuh dengan subur, binatang kura-kura, ikan dan berbagai jenis satwa laut lainnya tampak senang berenang di lautan. Sementara pada tahun 2008 digambarkan pulau Bali yang gersang, tanpa tumbuhan. Ikan dan satwa lautpun tidak tampak dalam gambar tersebut.

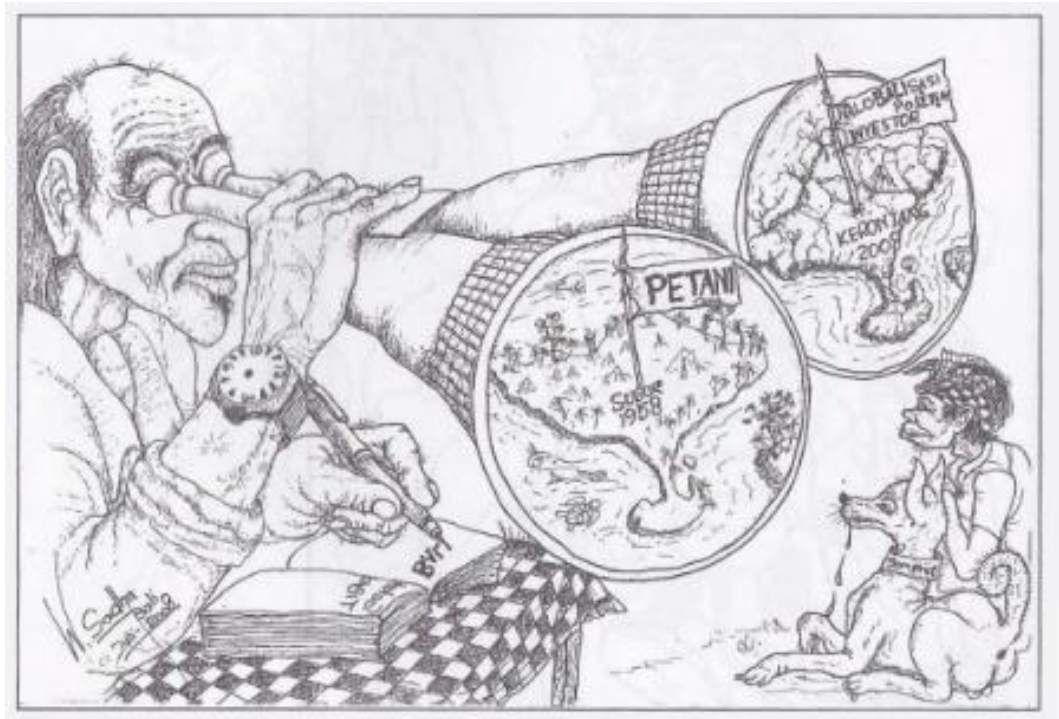

Gambar 2. Kartun Sompret Karya I Wayan Sadha tahun 2008

Secara konotasi kartun 2 ini memiliki makna perubahan Bali dari tahun 1958 sampai tahun 2008. Perubahan tersebut dipacu karena adanya arus globalisasi yang telah hadir di Bali. Masyarakat Bali larut dalam suasana perubahan yang kurang memikirkan dampak yang akan dimunculkan atas berbagai modernitas yang masuk. Jam yang digunakan oleh lelaki besar tentu bermakna sebagai waktu atau sebuah perubahan, dan berbagai perubahan tersebut dicatat dengan pengamatan. Sadha dalam kartunnya tidak menghadirkan persoalan dalam ilustrasi dengan ukuran besar, namun persoalan menukik pada halhal yang digambarkan kecil. Persoalan juga sering dihadirkan pada penggambaran latar belakang.

Catatan yang dibuat oleh manusia paling kiri ini menuliskan berbagai perubahan yang terjadi di Bali kurun Waktu 1958-2008. Jelas masukan arus globalisasi memberikan dampak perubahan pada Bali. Semenjak Bali dijadikan destinasi pariwisata sejak masa colonial, Bali yang tradisional terbentuk dari kebijakan Baliseering, kemudian bertemu pada arus global Kartun 2. Kartun Sompret Karya I Wayan Sadha tahun 2008 atau modernism yang dibawa oleh para wisatawan 'Barat'. Arus modernitas memang tidak bisa dihindarkan 
terkait dengan masuknya wisatawan mancanegara ke Bali.

Bali tahun 1958 adalah Bali yang dipandang oleh Sadha sebagai Bali yang subur. Keharmonisan antara masyarakat Bali dengan lingkungannya terjaga dengan baik, sehingga tanaman tumbuh dengan sangat baik. Ekosistem masih sangat baik. Tanaman tumbuh subur, satwa hidup tanpa adanya polusi. Petanipun mengibarkan benderanya sebagai tanda kejayaan pertanian. Pertanian tumbuh subur, masyarakat menikmati panen dengan hasil yang melimpah. Bali dengan budaya dan mata pencahaiannya sebagai petani tumbuh dengan sangat dinikmati oleh masayarakat.

Tahun 2008 bendera petani berganti oleh bendera Globalisasi-politik-investor. Kejayaan petani berganti karena tahun 2008 kejayaan dipegang oleh globalisasi-politik dan investor. Globalisasi yang dimaksudkan pada karya ini adalah masuknya pengaruh 'Barat' ke dalam budaya tradisional Bali. Perubahan yang dapat kita saksikan di Bali misalnya dalam budaya yang berkaitan dengan tari dan bentuk Barong. Pesatnya perkembangan pariwisata juga memberikan dampak bagi para sangging pembuat Barong. Hal ini menimbulkan perubahan secara substitusi, kompleks unsur-unsur kebudayaan (seperti Barong) yang ada sebelumnya mengalami perubahan fungsi, melibatkan perubahan struktural minimal. Para sangging telah banyak mengembangkan pekerjaannya. Dahulu mereka biasanya membuat Barong yang bersifat sakral, yang digunakan sebagai persembahan untuk upacara keagamaan. Taritarian Barong yang mereka buat pun bertujuan untuk menjaga keseimbangan desa, namun sekarang banyak di antara mereka yang mulai menerima pesanan untuk membuat Barong yang sifatnya komersil baik dari wisatawan domestik maupun wisatawa mancanegara. Hal ini menandakan bahwa Barong sekarang bukan saja di buat dalam wujud yang sakral, namun sudah mulai dimodifikasi menjadi benda kerajinan yang bersifat komersil. Tarian Barong pun tidak saja dilakukan pada saatsaat tertentu pada upacara keagamaan, tetapi sudah biasa dipentaskan di hotelhotel sebagai tarian profan.

Perubahan terhadap lingkungan juga sangat berdampak. Dalam bidang pertanian yang semula petani membajak sawahnya menggunakan sampi, namun hari ini para petani di Bali membajak sawah menggunakan traktor. Pemanfaatan pupuk alami untuk kesuburan tanah sawah sekarang berubah menjadi pemanfaatkan pupuk non-organik. Selain itu masuknya arus modernitas juga menghadirkan berbagai sampah plastik. Awalnya penjual makanan di Bali memanfaatkan produk tradisional seperti daun pisang dalam mengemas makanan, namun hari ini kemasan banyak menggunakan plastik. Plastik telah lama menjadi bencana yang telah terbukti banyak membahayakan bagi ekosistem. Plastik telah merusak ekosistem laut. Banyaknya kurakura, paus dan berbagai satwa laut lainnya mati karena terjerat plastik. Hal inilah yang menyebabkan gambran Bali tahun 2008 tidak tampak adanya satwa laut pada kartun tersbut.

Banyaknya investor yang telah mebangun hotel dan berbagai tempat penginapan sebagai bagian penunjang pariwisata juga telah mengubah tanah Bali yang awalnya daerah atau tanah persawahan menjadi bangunan. Ditambah Bali sebagai daerah pariwisata telah 'mengundang' banyak orang untuk datang ke Bali mencari kerja. Datangnya turis mancanegara ke Bali telah membuka banyak 
peluang kerja, maka ada banyak orang dari berbagai daerah datang ke Bali.

Banyaknya orang-orang datang ke Bali membuat perlunya banyak dibuatkan hunian tempat tinggal. Karena alasan keperluan tempat tinggal inilah kemudian para investor hadir untuk membuka kawasan hunian. Rumah Hunian dibangun dan mempersempit lahan pertanian. Sawahsawah telah berubah menjadi bangunan tempat tinggal. Banyak petani kehilangan sawahnya. Atas peristiwa tersebut, maka ilustrasi paling kanan hadir untuk menunjukan bahwa orang Bali hanya bisa duduk diam melihat perkembangan arus globalisasi dan kapitalisme. Persoalan inilah yang diporet oleh Sadha dalam kartun Sompret yang dibuat. Dalam masyarakat pra-kapitalis, pengambilalihan-apakah hanya untuk memenuhi kebutuhan materiil masyarakat atau untuk meningkatkan kekayaan para pengeksploitasi bisa dikatakan berwujud dalam sebuah bentuk absolut; memeras lebih banyak dari produsen langsung daripada peningkatan produktivitas tenaga kerja. Artinya, sebagai aturan umum, eksploitasi pra-kapitalisme terjadi dengan cara 'ekstra-ekonomi' yaitu dengan cara paksaan langsung menggunakan politik dan hukum demi mengekstraksikan surplus dari produsen langsung yang biasanya tetap memiliki sarana produksi.

$$
\text { Desakan-desakan ekonomi }
$$

kapitalisme dapat dikatakan telah menciptakan tatanan global yang lebih terintegrasi daripada sebelumnya, bahkan mungkin suatu bentuk integritas yang untuk pertama kalinya mewujudkan apa yang disebut oleh sebagian orang sebagai masyarakat global. Tetapi system sosial yang menyatukan berbagai jejaring sosial dan ekonomi nasional yang luas dan beragam adalah jenis system sosial yang sangat khas.

\section{PENUTUP}

\section{Simpulan}

Kartun Sompret karya I Wayan Sadha menghadirkan Bali dalam posisi yang terimbas arus global. Kehadiran budaya melalui penggambaran ilustrasi orang Bali yang berpakaian adat. Kartun-kartun menggambarkan persoalan masuknya arus globalisasi dalam budaya tradisional Bali. Secara komunikasi visual kartun ini menghadirkan ilustrasi, tipografi, warna dan layout. Ilustrasi memghadirkan manusia Bali memakai destar sebagai representasi orang Bali dalam budaya tradisional, serta ilustrasi yang tanpa destar sebagai representasi orang Bali yang telah masuk pada budaya modern. Tipografi yang digunakan memanfaatkan jenis huruf display untuk menghadirkan percakapan dan memperjelas keterangan gambar. Hurufhuruf yang digunakan memberikan penjelasan terhadap persoalan yang diangkat sebagai opini Sadha dalam melihat persoalan Bali. Kartun Sompret karya Sadha hanya memanfaatkan garis, tanpa warna, sehingga karya-karyanya tampak sebagai kartun hitam putih. Dengan layout komposisi keseimbangan simetris dan keseimbangan tersembunyi dengan perspektif pandangan sejajar manusia dan perspektif mata burung.

Secara denotasi, kartun Sompret karya Sadha menghadirkan narasi peristiwa terhadap persoalan yang dimunculkan berkaitan budaya tradisional Bali dan arus globalisasi. Cerita ini dibuat dalam kartun satu panel dengan percakapan beberapa ilustrasi tokoh atau dengan penggambaran tanpa percakapan. Dengan narasi yang dibangun, makna konotasinya pun dapat dibaca. Secara konotasi kartun sompret 
sebagai kartun opini memiliki makna arus globalisasi atau modern di Bali. Sebagai sebuah karya Kartun, Sompret sangat mampu menghadirkan paradoks persoalan. Refleksi sebuah peristiwa secara visual dihadirkan penuh kritik dan penyadaran.

\section{DAFTAR PUSTAKA}

Ajidarma,Seno Gumira. 2012. Antara Tawa dan Bahaya, Kartun Dalam Politik Humor. Jakarta :Kepustakaan Populer Gramedia.

Eco, Umberto. 2009. Teori Semiotika; Signifikasi Komunikasi, Teori Kode, Serta Teori Produksi-Tanda. Yogyakarta: Kreasi Wacana.

Fiske,John. 2007. Cultural and Communicaton Studies; Sebuah Pengantar Paling Komprehensip. Yogyakarta: Jalasutra

https://ejournal.ihdn.ac.id/index.php/Vidya Duta/article/view/2354/1791

https://ejournal.ihdn.ac.id/index.php/Vidya Duta/article/view/2359

Moleong, Lexy J. 2001. Metodelogi Penelitian Kualitatif. Bandung : Remaja Rosdakarya

Nuriarta, I. W. (2019). Kajian Semiotika Kartun Majalah Tempo Tahun 2019. Jurnal Seni Rupa Dan Desain, 23(1), 1115. Retrieved from https://jurnal.isidps.ac.id/index.php/prabangkara/arti cle/view/736

Picard, Michel. 2006. Bali; Pariwisata Budaya dan Budaya Pariwisata. Jakarta :Kepustakaan Populer Gramedia

Piliang, Yasraf Amir. 2012. Semiotika dan Hipersemiotika. Bandung : Matahari

Vivian .2008. Teori Komunikasi Massa. Bandung :PT Remaja Rosdakarya Wijana, I Dewa Putu. 2003. Kartun. Yogyakarta: Ombak 